\title{
Blood hematological values of Barb horses in Algeria
}

\author{
Mira Chikhaoui*, Fadhéla Smail and Fouzia Adda \\ Department of Animal Health, Veterinary Sciences Institute, Ibn Khaldoun University, Tiaret 14000, Algeria
}

\begin{abstract}
The Barb horse this famous Maghreb horse, symbol of the pride of the Berber peoples It is particularly significant in the Algerian history, tradition and culture. This study consists in establishing the hematologic values specific to the Barb horse in the national stud farm "Chaou-Chaoua" in Tiaret. Algeria. Age of the study animals varied between 1 and 23 years. The effects of age and sex were analyzed by dividing animals into four groups, A ( $1-2$ years, $n=5), B$ (3-5 years, $n=5), C(5-10$ years, $n=5)$ and $D(11-23$ years, $n=5)$; for females and $E(2-3$ years, $n=5), F(5-7, n=5), G$ $(10, n=5)$ and $\mathrm{H}(11-25, \mathrm{n}=5)$ for males. Animals studied were clinically healthy. A blood sampling was carried out from all study animals, the following hematologic variables have been determined: erytrocytes (RBC), hematocrit $(\mathrm{Ht})$, hemoglobin $(\mathrm{Hb})$, mean cell volume (MCV), mean corpuscular hemoglobin concentration (MCHC), mean hemoglobin content (MHC), white blood cells (WBC), neutrophils, eosinophils, basophils, lymphocytes, monocytes, platelets, total number of platelets (PLT) and mean platelet volume (MPV). The obtained results showed that the hematologic values are within established standards for the other breeds of hot-blooded horses; these values approached the lower limits of the standards for the RBCs, HCT, Hb, WBCs and the lymphocytes. Statically significant $(\mathrm{P}<0.05)$ differences were observed between females in different age groups for the MCV, MCHC, Platelets and the MPV. Groups of males showed significant differences for lymphocytes and platelets and between males and females, significant differences related to the MCV, Neutrophils, Basophils Monocytes, Platelet and the MPV. This research showed that these hematologic parameters are weak, they approach the lower limits of the standards and that neither the age, nor the sex seem to have an influence on the hematologic values of the Barb horse. Keywords: Age, Barb horse, Hematological parameters, Hematology, Sex.
\end{abstract}

\section{Introduction}

The Barb is one of the oldest equine breeds in the world; it would have settled during prehistory in North Africa thus, this breed is indigenous of the Maghreb region (Algeria, Libya, Morocco, Mauritania and Tunisia) (Bataille, 2008).

The Barb breed is a race susceptible to multiple variations due to its aptitude for adaptation to various environmental conditions, as well as the vast expanse of its cradle (North Africa) thus it is not uncommon to find multiple types of Barb. These variations are marked even at the individual level or more precisely at the blood level because of the various physiological factors (age, sex, food, gestation, stress, season...) being able to influence one or more blood parameters (Grutz, 2007).

It is often said that the various types of Barb come from their adaptation to the different regions of the Maghreb (according to their country of origin: Algeria, Morocco, Tunisia, Libya or Mali). The size and morphology of the Barb are different according to whether it develops from generations in areas of plains, mountains or in the northern boundary of the desert (Kadri, 2009).

It is a particularly rustic horse, of great sobriety, in particular under hot climates because of its resistance to dryness and climatic variations. He needs in particular a less food intake compared to horses of blood type Thoroughbred or the Selle Français. A famous saying on

him says that "he can hunger, he can thirst, he can cold, he can heat, never he is tired". The Barb acclimatizes itself perfectly to the life in the desert. Its highly reliable temperament makes an ideal horse for education. Calm, easy, balanced and brave, he is energetic and appreciates work. It is of an undeniable softness and an easy dressage (Bataille, 2008). The aim of the present study was to determine the reference hematologic values of the Barb, because the current standard values for blood testing are mainly compiled from data coming from horses of other breeds, and those cannot always be applied to many horses (Tyler et al., 1987; Radostits et al., 2000). Thus, if a veterinarian does not have laboratory reference values for the horse he examines, errors of diagnosis can occur. Consequently, blood samples were taken from 40 Barb horses of 1 to 23 years old in the national stud farm "Chaou-Chaoua" in Tiaret $\left(35^{\circ} 22^{\prime} 0^{\prime \prime} \mathrm{N}, 1^{\circ} 19^{\prime} 0^{\prime \prime} \mathrm{E}\right)$, and mean with standard deviation of 15 parameters were determined in order to establish hematologic reference values. Now, the stud farm of Tiaret constitutes the leading provider

*Corresponding Author: Mira Chikhaoui. Department of Animal Health, Veterinary Sciences Institute, Ibn Khaldoun 
of horses for races, while maintaining the "model" and the original type through a genetic capital of great value.

\section{Materials and Methods}

The present study was carried out on 40 horses (20 mares and 20 stallions) of Barb race aged from 1 to 23 years old. Effect of age was studied on four groups of mares: $A,(1-2$ years, $n=5)$; $B(3-5$ years, $n=5)$; $(5-10$ years, $\mathrm{n}=5) ; \mathrm{D}(11-23$ years, $\mathrm{n}=5)$ and four groups of horses: $\mathrm{E}(2-3$ years, $\mathrm{n}=5) ; \mathrm{F}(5-7$ years $\mathrm{n}=$ 5) ; $\mathrm{G}(10$ years, $\mathrm{n}=5)$ and $\mathrm{H}(11-25$ years, $\mathrm{n}=5)$. The food ration consisted of barley and hay, the water was served ad-libitum. The animals were clinically healthy. The horses were selected on the basis of standard clinical examination and no clinical symptoms of any disease were noted. A blood sample was taken on all subjects between 9:00 am and 10:00 am before the distribution of their ration. The blood samples were taken during the October and November. Venous blood from the jugular vein is removed using a 18 gauge needle mounted on a $10 \mathrm{CC}$ sterile syringe (KD-JECT ${ }^{\circledR}$ III, KDM®, Germany); then stored in test tube with K3EDTA $x 4 \mathrm{ml}$ (FL medical-ITALY) for hematological tests. In whole blood, the following are collected: red blood cell (RBC), hematocrit (Ht), hemoglobin $(\mathrm{Hb})$, mean corpuscular volume (MCV), mean hemoglobin concentration (MCHC), mean corpuscular hemoglobin $(\mathrm{MCH})$, white blood cells (WBC), platelets (PLT) and mean platelet volume (MPV) were determined using a hematology automaton, calibrated for the equine species (Orphee Mythic 18 Hematology Analyzer®). Differential blood count (neutrophils (NEU), eosinophils (EOS), basophils (BAS), monocytes (MON), lymphocytes (LYM) was determined on a blood smear using a light microscope at x 400 magnification. The blood smears were ethanol-fixed and stained according to the MayGrünwald-Giemsa technique

Obtained results were analyzed with one way ANOVA using STATISTICA 9.1 (StatSoft Inc., Tusla.). The results considered statitistically significant for $\mathrm{P}$ values lower than 0.05 .

\section{Results}

The mean value and the standard deviation for blood erythrocyte parameters, total and differential leukocyte count as well as the platelet formula are presented in Table 1 for all groups of females and males.

The mean value of the number of red blood cells (RBC), the hematocrit ( $\mathrm{Ht})$ and hemoglobin $(\mathrm{Hb})$ were close to the lower limit according to (Jain, 1986) for all groups, no difference was observed for these parameters.

Mean blood cell volume (MCV) and mean corpuscular concentration $\mathrm{Hb}$ (MCHC) were high for all groups, with a significant difference in females and in males and females $(\mathrm{p}<0.05)$. Mean corpuscular $\mathrm{Hb}(\mathrm{MCHC})$ was slightly higher in group A, with a significant difference in groups of females.

The number of leucocytes was normal for the female groups, however the groups of males $\mathrm{F}, \mathrm{G}$ and $\mathrm{H}$ had values below standards, no significant difference was found between the different groups. The average number of neutrophilic granulocytes in horses of the group $\mathrm{G}$ was below standard with a significant difference between groups of males. The mean value of eosinophils, basophils and lymphocytes was normal for all groups.

The number of monocytes was within standards regardless of the age group except for group $\mathrm{C}$ where the value was high; a significant difference was observed between groups of males. The average platelet count and mean platelet volume (MPV) were within standards (Jain, 1986) for all animals, but a significant difference was found in females, in males and between males and females.

\section{Discussion}

Hematological tests in horses helps in the clinical diagnosis of systemic, infectious diseases and some parasitic diseases. It can also provide important information on the treatment response and metabolic status of horses (Ricketts, 1987; Lassen and Swardson, 1995; Messer, 1995). Despite the prolonged use of hematology in equine medicine, interpretation can be a challenge in some cases because it can be influenced by a large number of factors. Hematologic parameters may vary according to breed, sex, age, reproductive status, physical form, training level, feeding, animal handling, blood sampling, degree of excitation and state of health (Jain, 1993; Rose and Hodgson 1994; Messer, 1995; Kramer, 2000). The groups of horses used in our study did not show large variations for most of the parameters according to age and sex. Red blood cell counts, $\mathrm{Ht}$ and $\mathrm{Hb}$ were within normal range for all groups with slight anemia in group B in females and group $\mathrm{H}$ in males. No sex difference has been observed for these indices according to studies of Gupta et al. (2005) and Harvey et al. (1984, 2005). For others, young horses and young adults had higher values than older ones (Robinson and Sprayberry, 2003; Feldman et al., 2006; Reed et al., 2010; Satue et al., 2012). This low rate of erythrocyte parameters could be due to a low food ration not adapted to their physiological needs. However, a study in pregnant mares of purebred Arabian breed living at the "chaouchaoua" farm in Tiaret under the same conditions showed higher levels of RBC, Ht and WBC (Meliani et al., 2014). Our results showed a MCV and an MCHC above normal values (Jain, 1986) for all groups. The low RBC values are compensated by an increase in RBC size (Satue et al., 2009), but no differences between males and females, unlike other studies for which females have a higher $\mathrm{MCH}$ and MCHC than males. 
Table 1. Haematological indices in Barb equids of different age and sex groups (standards Adapted from Jain (1986)).

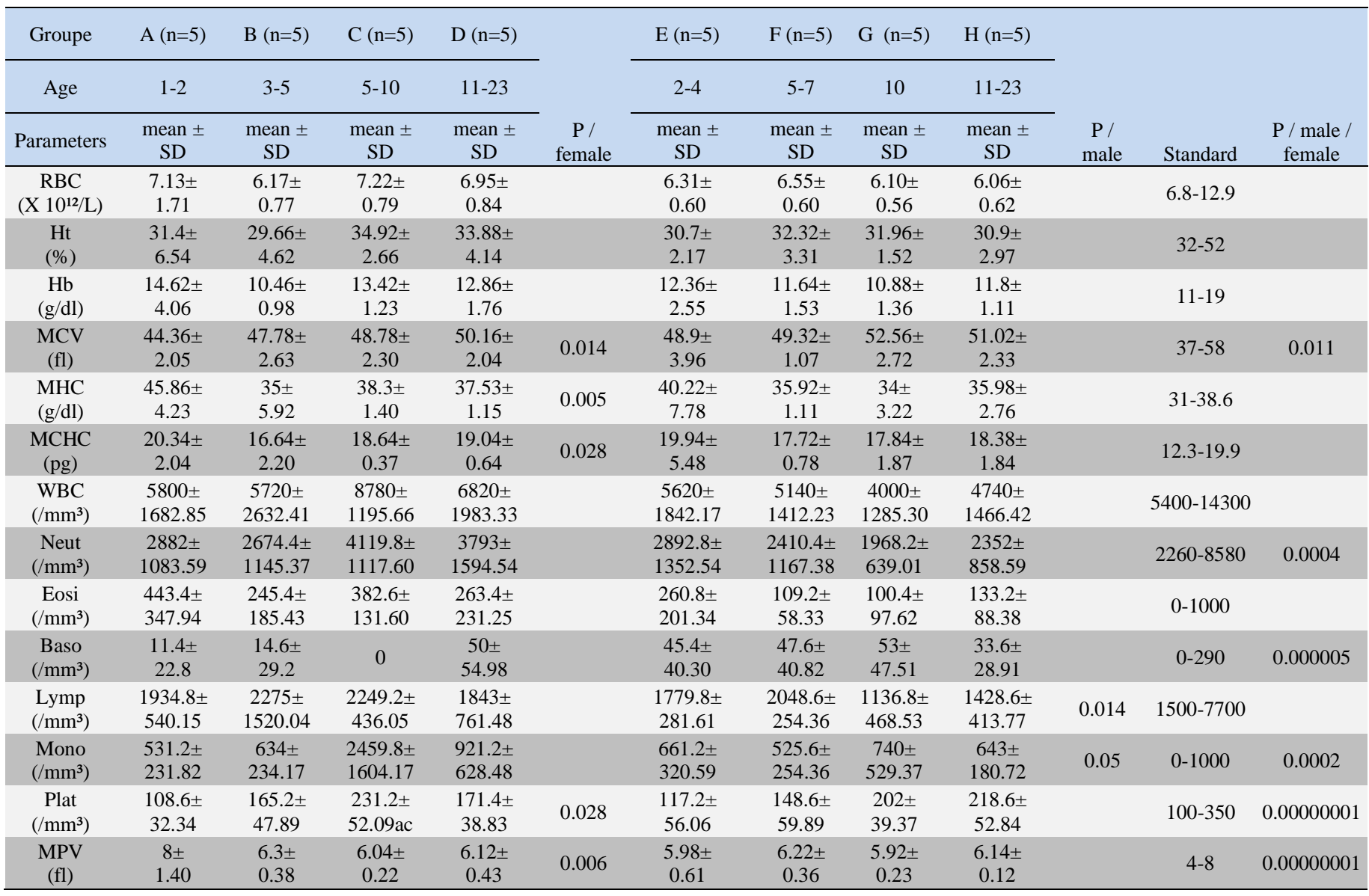

Hematological differences related to sex seem to be of limited importance in horses. Indeed, minor differences between adult females and males were reported in our study. However, the results of research in this area are controversial. Males have higher red blood cells, $\mathrm{Hb}$ and $\mathrm{Ht}$, while females have higher $\mathrm{MCH}$ and $\mathrm{MCHC}$ (Jain, 1986; Hernández et al., 2008; Satue et al., 2009). On the other hand, Gill and Rastawicka (1986) observed in Thoroughbred and Quarter horses that RBC, Ht and HB were higher in mares than in males. Persson and Ullberg (1974) reported that hematological values were higher in stallions, probably because of the effect of androgens on erythropoiesis.

In our study the WBC values were normal according to (Jain, 1986) for females and males in groups F, G and $\mathrm{H}$ had slightly lower values. The usual values often give fairly wide intervals [5.4 to $10.310^{3}$ ] because some agerelated variations are not taken into account, (Ralston et al., 1988; McFarlane et al., 2001). The number of RBC decreases with age. This significant decrease with age could be linked to a reduction in regeneration capacity (Fermaglich and Horohov, 2002). A similar decrease in age-related $\mathrm{RBC}$ and WBC values has been reported for other warm-blooded horses (Feldman et al., 2006). Basophils had a low percentage in our study. McFarlane et al. (2001) found an average of $49 \mathrm{C} / \mathrm{mm}^{3}$ in young horses and $58 \mathrm{C} / \mathrm{mm}^{3}$ in older horses less than $100 \mathrm{C} / \mathrm{mm}^{3}$. This is similar to our result, however basophil levels were higher in males than females with a significant difference in males and females. The rate of lymphocytes was in the standards for all females , however, it was substandard for older males. McFarlane et al. (2001) found a significant decrease in the number of lymphocytes in older horses, there is an alteration age-related immune system in the equine species. Moderate lymphocytosis (6 to $10.10^{3} / \mathrm{mm}^{3}$ ) is sometimes found in "physiological" leukocytosis related to fear or pain but also after antigenic stimulation (Nguyen et al., 2007). Age did not seem to affect the number of monocytes (McFarlane et al., 2001). This is similar to our results. Group C in our study had leukocytosis. it could be a sign of chronic inflammation (Fortier et al., 2008). The number of platelets increased with age. Results findings on this topic are controversial. Some authors found platelet decrease in horses (Ralston et al., 1988; Jain, 1993; Satue et al., 2008), while others found no significant differences in older horses (McFarlane et al., 1998). 


\section{Conclusions}

Neither age nor sex influences hematological values in the Barb horse. They are closer to that of the coldblooded horses (Jain, 1993) this is probably related to his temperament.

For this reason, many hematological variables in Barb horses may be lower than the reference values described for other equine breeds, making the diagnosis of mild anemia difficult in some cases.

\section{Conflict of interest}

The authors declare that there is no conflict of interest.

\section{References}

Bataille, L. 2008. «Barbe», dans Races équines de France, France Agricole Editions, (ISBN 2855571545 et 9782855571546 , lire en ligne [archive]), pp: 41-46.

Feldman, F.B., Zinkl, G.J. and Jain, N.C. 2006. Schalm's veterinary hematology. $5^{\text {th }}$ ed. Blackwell Publishing, Ltd.

Fermaglich, D. and Horohov, D. 2002. The effect of aging on immune responses. Vet. Clin. North Am. Equine Pract, 18, 621-630.

Fortier, G., Pronost, S., Miszczak, F., Fortier, C., Leon, A., Richard, E., Van Erck, E., Thiry, E. and Lekeux, P. 2008. Identification of equid herpesvirus-5 in respiratory liquids: A retrospective study of 785 samples taken in 2006-2007. Vet. J. 182(2), 346348.

Gill, J. and Rastawicka, M. 1986. Diurnal changes in the hematological indices in the blood of racing Arabian horses. Pol. Arch. Weter 26(1-2), 169-179.

Grutz, J.W. 2007. "The Barb", Saudi Aramco World, http://archive.aramcoworld.com/issue/200701/the. barb.htm. Accessed 23 February 2017.

Gupta, A.K., Pal, Y., Tandon, S.N. and Dwivedi, S.K. 2005. Haematological and biochemical blood profiles in healthy Indian Spiti horses. Indian Vet. J. 82, 604-608.

Harvey, R.B., Hambright, M.B. and Rowe, L.D. 1984. Clinical biochemical and hematologic values of the American Miniature Horse: reference values. Am. J. Vet. Res. 45(5), 987-990.

Harvey, J.W., Pate, M., Kivipelto, J. and Asquith, R. 2005. Clinical biochemistry of pregnant and nursing mares. Vet. Clin. Pathol. 34(3), 248-254.

Hernández, A.M., Satué, K., Lorente, C., Garcés, C. and O'connor, J.E. 2008. The influence of age and gender on haematological parameters in Spanish Horses. Proceeding of FEEVA Meeting - XIV SIVE Congress, Venice (Italy), pp: 956-977.

Jain, N.C. 1986. The horse. Normal haematologic with comments on response to disease. In: Schalm's Veterinary Hematology. Jain N.C. (ed.), Lea \& Febiger, ISBN 08121094229780812109429 , Philadelaphia, USA, pp: 140-177.
Jain, N.C. 1993. Comparative hematology of common domestic animals. In: Essentials of Veterinary Hematology, Jain NC., (ed.), Lea \& Febiger, ISBN 0-6121-1437-X, Philadelphia, pp: 19-53.

Kadri, K. 2009. Le Barbe: cheval de légende. Zaki Bouzid edition.

Kramer, J.W. 2000. Normal hematology of the horse. In: Feldman, B.F., Zinkl, J.G. and Jain, N.E. (eds.): Schalm's Veterinary Hematology. Lippincott Williams \& Wilkins, Philadelphia, PA, pp: 10691074.

Lassen, E.D. and Swardson, C.J. 1995. Hematology and hemostasis in the horse: normal functions and common abnormalities. Vet. Clin. North Am. Equine Pract. 11, 351-389.

McFarlane, D., Sellon, D.C., Gaffney, D., Hedgpeth, V., Papich, M. and Gibbs, S. 1998. Hematologic and serum biochemical variables and plasma corticotropin concentration in healthy aged horses. Am. J. Vet. Res. 59, 1247-1251.

McFarlane, D., Sellon, D. and Gibbs, S. 2001. Age related quantitative alterations in lymphocyte subsets and immunoglobulin isotypes in healthy horses. Am. J. Vet. Res. 62, 1413-1417.

Meliani, S., Benallou, B., Hamdi, A. and Bouabdelli, S. 2014. Influence of Age on Haematological Parameters in Post-Partum Pure Bred Arabian Mares Raised in Tiaret Algeria. J. Microb. Biochem. Technol. 7, 8-10.

Messer, N.T. 1995. The use of laboratory test in equine practice. Vet. Clin. Equine Pract, 11, 345-350.

Nguyen, H.H., Zemlin, M., Ivanov, I.I., Andrasi, J., Zemlin, C., Vu, H.L., Schelonka, R., Schroeder, H.W., Jr and Mestecky, J. 2007. Heterosubtypic immunity to influenza A virus infection requires a properly diversified antibody repertoire. J. Virol. 81, 9331-9338.

Persson, S.G.B. and Ullberg, L. 1974. Blood volume in relation to exercise tolerance in trotters. J. South African Vet. Assoc. 45(4), 293-299.

Radostits, O.M., Gay, C.C., Blood, D.C. and Hinchcliff, K.W. 2000. Reference laboratory values, Appendix. In: Veterinary Medicine, $9^{\text {th }}$ ed., W.B. Saunders, Edinburgh, pp: 1819-1822.

Ralston, S.L., Nockels, C.F. and Squires, E.L. 1988. Differences in diagnostic test results and haematologic data between aged and young horses. Am. J. Vet. Res. 49(8), 1387-1392.

Reed, S., Bayly, W. and Sellon, D. 2010. Equine internal medicine. Sauners, $3^{\text {rd }}$ ed. pp: 1466.

Ricketts, SW. 1987. The laboratory as an aid to clinical disorders. Vet. Clin. North Am. Equine Pract. 3, 445-460.

Robinson, N.E. and Sprayberry, K.A. 2003. Current therapy in equine medicine, $5^{\text {th }}$ ed. Elsevier Saunders, pp: 956-977. 
Rose, R.J. and Hodgson, D.R. 1994. Hematology and biochemistry. In: Hodgson, D.R. and Rose, R.J. (eds.). Theathletic horse, principles and practice of equine sports medicine. WB Saunders, Philadelphia, PA, pp: 63-76.

Satue, K., Hernandez, A. and Lorente, C. 2008. Erythrocyte parameters in Spanish horse: influence of age and gen der. In: Proceedings of $10^{\text {th }}$ Annual Congress of the European Society of Veterinary Clinical Pathology (ESVCP) and the $8^{\text {th }}$ Biennial Congress of the International Society for Animal Clinical Pathology (ISACP), ESVCP, CAB Abstracts, Barcelona, Spain, pp: 163-164.
Satue, K., Blanco, O. and Muñoz, A. 2009. Age-related differences in the hematological profile of Andalusian broodmares of Carthusian strain. Vet. Med. 54(4), 175-182.

Satue, K., Hernandez, A. and Muñoz, A. 2012. Physiological Factors in the Interpretation of Equine Hematological Profile. From: Hematology Science and Practice, Dr. Charles Lawrie (Ed.), pp: 573-596.

Tyler, R.D., Cowell, R.L., Clinkenbeard, K.D. and MacAllister, C.G. 1987. Hematologic values in horses and interpretation of hematologic data. Vet. Clin. North Am. Equine Pract. 3, 461-484. 